\title{
A Study on the Impact of Supplier Performance towards Achieving Retailer Satisfaction
}

\author{
Carmen $\mathrm{Ng}^{1}$, Chua Yi Min ${ }^{1}$, and Dazmin Daud ${ }^{1 *}$ \\ ${ }^{1}$ Faculty of Business and Information Science, UCSI University, Jalan Menara Gading, 56000 Cheras, Kuala Lumpur, Malaysia.
}

\begin{abstract}
Nowadays, the objective of achieving customer satisfaction has become more and more important in order to maintain organization's competitive advantage within its industry. This study aims to identify the supplier's performance focuses on the service quality present provided to retailers. The independent variables for this study include reliability, responsiveness, assurance, empathy, tangible and consistency. This study was conducted among retailers in Taman Connaught, Cheras and the interview questionnaires were distributed to 5 respondents to test the degree of satisfaction in terms of the five components of service quality and consistency. The collected data was analyzed by classified the respondents into respective groups namely "satisfied retailers" and "dissatisfied retailers". This study provides several constructive recommendations to the suppliers to improve their performance such as create a commitment, track mistakes, invest in training and development and organize quality circles.
\end{abstract}

\section{INTRODUCTION}

Supply chain management (SCM) mainly revolves between suppliers and customers (retailers), when suppliers form an efficient relationship with retailers, both parties will suffer individual loss such as delayed in delivery of goods and restock inventory [1]. Once there is a delay in delivery of goods, there will be delay in terms of payment by retailers to suppliers too. However, if there is cooperation between suppliers and retailers, good outcomes can be observed such as on-time delivery and availability of optimum inventory on shelves.

Based on the supply chain research done by Westbrook and Frohlich (2001), they explained that in supply chain, if the level of integration between supplier and customer is high, then there will be more possibilities of gaining potential benefits. This includes better co-ordination between supplier and customer, waste reduction, reduction in uncertainty and variability that will lead to greater efficiency along with faster delivery performance [2].

From the perspective of customers, 'best suppliers' are defined as those who are reliable and always be able to deliver their services efficiently. As a result, the 'best suppliers' will have good relationship with their customers. It is therefore, imperative to have a systematic and objective supplier selection method and this need to be followed by a supplier evaluation process [3, 4].

In a study conducted by Agbor (2011), the product quality, price, availability, reliability, responsiveness and customer service are all essential factors in identifying suppliers' performance [5]. However, different scale of suppliers' business will cause different result in their performance. A good supplier will have the ability and capability to provide additional products to their customers and thus reduce the needs of customers to work with numerous suppliers [6]. The effective communication can benefit both of the parties as it will be able to avoid problems such as delays of the delivery, product nonconformities and those problems that are associated with product quality and quantity. Thus, a good supplier will know how to make their customers satisfied by communicating effectively with them [7].

According to the research conducted by Othman and Ghani (2008), they have mentioned that a positive supplier-retailer connection relies on the action of suppliers in developing precise HRM code of practices that will allow them to satisfy their customer's requirements [8]. Hence, given a situation a retailer has made an order for 500 units of tomato ketchup 2 days earlier prior to their supplier's terms of notice, thus, although the amount ordered has exceeded the standard ordering amount, the Chief Logistics Officer must be able to fulfilled their customer expectations - to create retailer's satisfaction.

When retailer's expectations are met, this means that there is presence of the supplier's service quality provided. Based on a research carried out by Giovanis and Binioris (2014), it is mentioned that there is a strong interconnection between the five components of service quality and the satisfaction of customers that is exercised to prioritize strategic plans of companies in the supply chains [9]. This meant that the 5 components of service qualities such as Reliability, Responsiveness, Assurance Empathy and Tangibles needs to be taken into

*Corresponding author's e-mail: dazmindaud@ucsiuniversity.edu.my 
consideration by identifying the right components (dividing into major and minor) to be applied to the right retailers. When the right components are accessed, suppliers will then analyzed their strengths and weaknesses in these identified "components", and try to improve their present service quality. As a result, customer satisfaction can be achieved.

Therefore, this study is identifying the five components of service quality with an additional of consistency aspect through conducting a interview with the retailers and the recommendations to the management process of their supplier in determining the effectiveness of the existing workflow also discussed.

\section{METHODOLOGY}

This study used qualitative method to study the factors that impact the retailers' satisfaction towards the suppliers' performance. Qualitative approach contributes insights and gain understanding of underlying reasons and motivation. Furthermore, qualitative research could also uncover prevalent trends in thought and opinion.

The qualitative methodology was utilized to evaluate the correlation between the independent variable which are the five components of service quality and an additional component of consistency and also the dependent variable (retailers' satisfaction). Semistructured interview was chosen in the study because it helps to give meaningful elaborations to the areas that will be explored; meanwhile it allows the researchers or respondents to deviate so that this can help to seek a creative idea or a response that is given in a more detailed way.

\subsection{Sampling Design}

\subsubsection{Sampling Unit}

In this interview questionnaire, the targeted population is towards a few handpicked retailers who are running a convenience store or restaurant business in Taman Connaught, Cheras area. The respondents must be the person who works as a managerial position of the business.

\subsubsection{Sampling Size}

In choosing the most appropriate sample size in a qualitative research, there is no presence of specific rules to abide. For instance, for the area of phenomenological studies, it is to be recommended by Creswell (1998) that the optimum amount is between 5 to 25 interviews [10]. Since there is not a specific standard to be followed when deciding the sample size, thus 5 respondents were targeted in this study for conducting interviews with the retailers within Taman Connaught area.

\subsubsection{Sampling Technique}

Preliminary data can be attained in the fastest and cheapest method through non-probability sampling and it is the simplest form of sampling and there is no restriction in the selection process and it is not difficult to apply in this study as the respondents are selected from most readily available source [11].

Convenience sampling is being selected as the sampling method for this study because of its convenient accessibility and proximity to the researcher. The process of filtering the right respondents to be interviewed which helps to ensure the respondents are qualified to be able to answer the questionnaire set. The whole sampling process is being held in shop-lot that located in Taman Connaught area and 5 respondents who work as a managerial position of the business were participated to study the factors that impact the retailers' satisfaction towards the suppliers' performance.

\subsection{Questionnaire Design}

The questionnaire is designed into two separate parts whereby the first part (Part A) consists of the demographic details of the chosen respondents such as their name, age, sex and the marital status [12 - 16]. On the other hand, in the second part (Part B) is to have evidence about measuring the respondents' opinion about the independent variables (reliability, responsiveness, assurance, empathy, tangibles and consistency) that caused an impact on their satisfaction towards the suppliers' performance. 5 questions of each variable will be asked and respondents will need to answer to the questions based on their own opinions, and explain further for it. In this study, researchers used direct questions to set the questionnaires to study the factors that influence retailers' satisfaction.

\subsection{Scale of Measurement}

This is qualitative study, thus it depends prominently on words as a usage as its analysis units and its way of understanding. Thus, the spoken word of the respondents during the interviews is evaluated. The feedback from the respondents outlined which variables (reliability, responsiveness, assurance, empathy, tangibles and consistency) affect most to their level of satisfaction. Meanwhile, the conversations with the respondents will also be transcribed during the interviews before the data can be analyzed.

\subsection{Data Collection}

The primary data are gathered from semi-structured interview sessions based on a set of open-ended questionnaire. These questionnaires are asked and guided during the interview in order to ensure that valid and reliable data from the respondents can be obtained. The respondents can have a thorough understanding before they answer the questions. On the other hand, data can be extracted from related journal articles, e-books and useful online resources from the Web and these will be 
used as secondary data. The use of secondary data is to provide a brief idea and guidelines in conducting this study.

\subsection{Data Analysis Methods}

The topic of this study is to access to the supplier's performance towards retailer's satisfaction, data can be constantly compared through coding, which is selective coding. Selective coding is the construction of a plot that connects the available categories that are formed. It is a process whereby one category is picked to be the core category, and can relate with all other categories to that category. By applying this concept, the core category of this study is "supplier's performance", the other categories are the five components of service quality and an additional component of consistency.

\subsection{Pilot Study}

A test that runs before an actual interview questionnaire is distributed and asked carefully to respondents is called a pre-test, it is a research tool designed for the application of "pilot study" [17]. It is crucial in trying to perform a pilot study, "Pilot test first, Do not take the risks" [18]. Some additional information can be put into the questionnaire as a form of improvement, only if this pilot study is held smoothly. Hence, since this study will be conducted in Taman Connaught, Cheras, a pilot study is done by distributing 5 interview questionnaires to specific retailers chosen and amend the design of the questionnaire structure based on their feedbacks.

\section{RESULT AND DISCUSSION}

\subsection{Validity Test}

In content validity, it is measuring instrument to which it provides adequate coverage of the investigative guiding to the study $[14,16]$. Thus, a list of questions has been prepared to be interviewed to the selecting respondents which are from different business category in retailing industry. As mentioned in the methodology, the interview questionnaires which are prepared for the respondents are related to this study title, which is the impact of supplier's performance towards achieving retailer's satisfaction. In the questionnaire, it was focused on the performance of the supplier's Reliability, Responsiveness, Assurance, Empathy, Tangible and Consistency.

\subsection{The background of respondents}

Respondent 1 is a 29 years old supervisor from Life Tree Café, namely Low Wai Chi who is a diploma holder and she personally feels average about the supplier's performance.

Respondent 2 is a 30 years old manager from Bookmark Coffee, namely Leow Wei Kai who is a
Bachelor degree holder and he personally feels excellent about the supplier's performance.

Respondent 3 is a 25 years old manager from Craft Café, namely Eric Yong who is a diploma holder and he personally feels average about the supplier's performance.

Respondent 4 is a 27 years supervisor from Colwyn Copy \& Printing Shop, namely Jesz who is a SPM holder and she personally feels average about the supplier's performance.

Respondent 5 is a 21 years supervisor from Gadget Plus Phone Accessories Shop, namely David who is a SPM holder and he personally feels average about the supplier's performance.

\subsection{The retailer's satisfaction towards their supplier's performance}

\subsubsection{Reliability}

Respondent 1 considered that the supplier did deliver the ordered goods on time and the schedules of delivery are fixed according to the preference of the respondent. The goods are always in right quantity and good condition, but the price of the goods will sometimes fluctuate according to the market condition.

Respondent 2 claims that the supplier always delivers as promised in contract. The goods are in right quantity but not always in good condition. The supplier has procedures to assess and manage identified risks relating to the cost of goods that cause by economic depression.

Respondent 3 thinks that the supplier may postpone the date or the time of delivery. The respondent never received any information from the supplier about the changing of the price of goods ordered. The quality of the goods is not always in good condition.

Respondent 4 said the supplier has performed their job well with no late delivery. The supplier has a very strong and good management flow of their business model. The goods are in right quantity and good condition. The prices that the supplier offered are always fixed and as to agreed.

Respondent 5 claims that the supplier's delivery service is always right on time. Respondent is satisfied with the supplier's performance in delivering the right quantity of goods. The goods received are always in good-shape.

\subsubsection{Responsiveness}

Respondent 1 claims the supplier always took a long period of time to revert back to respondent's complaints. There is ' 8 out of 10' the respondent is satisfied with the supplier's capability in dealing with their requests. The supplier did well in accommodating with the respondent's unexpected demands in terms of quality, quantity and timeliness.

Respondent 2 said the supplier usually takes 1 week to proceed with the respondent's complaints and requests. The supplier can accommodate the respondent's 
unexpected demand very well in term of quantity and timeliness.

Respondent 3 claims the supplier takes 2 to 3 days to proceed to respondent's complaints. There is '7.5 out of 10 ' the respondent is satisfied with the supplier's capability to deal with their complaints. The supplier always did well in coping with unexpected demand required by the respondent in term of quantity and timeliness

Respondent 4 said the supplier did well in meeting the respondent's unexpected demands in terms of timeliness, quality and quantity. The respondent rated the supplier's responsiveness as ' 8 out of 10 '. The supplier are consuming up too much time to revert back to the respondent's requests.

Respondent 5 claims the supplier is able to fix the complaints and assists with the respondent's requests within 24 hours. The respondent has rated the supplier's ability to deal with complaints or requests at 7.5. Supplier performs at an average level in accommodating with the respondent's unexpected demand in term of quality.

\subsubsection{Assurance}

Respondent 1 said they could not observe any improvement made by the supplier. There is a room for improvement regarding to the supplier's ability to maintain level of performance. Reasonable price and good customer services are the reasons that respondent remain loyal to the supplier. Being responsible and accountable at work tasks meanwhile being a friend to each other is crucial to build trust and confidence

Respondent 2 claims the supplier will take 1 to 2 months to improve their quality of service. Supplier's performance is up to par, very consistent. Respondent maintained loyalty to the supplier due to the assurance in terms of quality.

Respondent 3 claims the supplier will take within one week to improve their quality of service. The supplier was rated as 'Average' by the respondent in aspect of maintaining the level of performance.

Respondent 4 said the supplier will usually take around one month to improve their quality of service. The supplier was rated as 'Good' by the respondent in aspect of maintaining the level of performance. Commitments from the supplier had built up a strong trust of bond from the respondent.

Respondent 5 claims the supplier usually takes a period of 2 weeks to improve their quality of service. Good quality, good after-sales service and most importantly reasonable price are the ways to build trust with the respondent.

\subsubsection{Empathy}

Respondent 1 claims the supplier would not make any compensation if they found out that they are at wrong. The co-operation as asked was not given to the respondent completely by the supplier.
Respondent 2 said the supplier provides empathy to the respondent by selling the ingredients at a cheaper rate after knowing the background of the café. The delivery time is set according to the café's preference, thus, it is a form of customization. There is co-operation given when the respondent had notified the supplier about areas of dissatisfaction

Respondent 3 claims the supplier did provide empathy to the respondent by adjusting their delivering schedule in order to coincide with the respondent's time. There is a co-operation given when the respondent had notified the supplier about the areas of dissatisfaction.

Respondent 4 said the supplier did provide empathy by knowing what kind of business that the respondent is running as well as by adjusting their delivering schedule in order to match with the respondent's time. The supplier will held a meeting with the respondent to follow up on the issues that the respondent has encountered.

Respondent 5 claims the supplier provides empathy by communicating with the main staffs working in the operations department to get a deeper knowledge about the company. The supplier has sat down with Respondent 5 to inquire about their preferences regarding to the delivery time. The supplier reacts patiently towards receiving critics directed by Respondent 5.

\subsubsection{Tangible}

Respondent 1 claims the suppliers are very well-aware of the type of goods to be delivered and will use suitable truck to transport the goods. The supplier will provide delivery order and invoice to the respondent.

Respondent 2 said refrigerated trucks are used to transport perishable items. The trucks used by the supplier are very well-maintained and are hygiene. The document "Proof of delivery" is given to the respondent once they receive the ordered goods.

Respondent 3 claims the vehicle that the supplier used to transport the goods are hygiene and also in good condition. The written documents are provided correctly each time after the delivering.

Respondent 4 said each of the stationeries will be placed in different size of cartons and each of the cartons is clearly labeled by name and code of the items. The vehicles used to transport the goods are in good condition. Right written document such as official receipt will be provided by the supplier.

Respondent 5 claims the mobile phone cases were wrapped with bubble wrap to protect them from being damage. Majority of the delivering trucks are very wellmaintained. The delivery order and invoice are passed to the respondent each time after delivering.

\subsubsection{Consistency}

Respondent 1 said there is a standardized quota set by the supplier regarding the charges included in the invoice. The supplier's systems are not aligned with the respondent's but the necessary documents and 
information are updated every time. The supplier's performance rarely fluctuates according to the seasons.

Respondent 2 claims the quota set for the service of delivery is standardized. The electronic data interchange is utilized by both parties for better integration of system. The supplier's performance did not fluctuate according to seasons.

Respondent 3 said the quota set for the service of delivery is standardized. The supplier did not often change their modes of payment. Most of the suppliers' performance did not fluctuate according to the seasons.

Respondent 4 claims the supplier always delivered the goods on time and case such as delay in receiving goods has rarely happened before. The quota set for the service of delivery is standardized. The term of payment or mode of payment has always been the same. The supplier will upgrade their own system yearly to remain having a consistent improvement.

Respondent 5 claims the supplier has a properlyplanned delivery schedule and deliveries are always on time. The supplier has a standardized quota set for each charges stated in the invoice. The mode of payment has always been the same. the supplier's system always works in the same line as the respondent's system.

\subsection{Recommendation}

Making a commitment means a supplier will be committed to give in their all positively to reach the highest customer satisfaction. A company's commitment to quality had to come from the top, and it had to be reinforced over and over again. Quality of a service will do down the drain if a business views quality as its single, non-negotiable goal, workers will inevitably feel the need to make trade-offs hence leading to this negative result. Therefore, the supplier's top management have to ensure that each of their employees in all levels are committed to perform efficiently, or else they can set a reward and award appreciation program for the bestperformed employee, in order to trigger their passion and willingness to provide the best attitude and service for their customers (retailers).

Tracking mistakes is easier said than done. Majority organizations do not have a proper measurement of to what is "good quality" but this however can be measure through feedbacks received from their customers (retailers). One way to gauge customer satisfaction is by tracking what is called a "net promoter score". A customer who answers 9 or 10 is seen as a promoter, a customer who answers 7 or 8 is seen as passive, and a customer who gives a company a score of 6 or lower is seen as a detractor. By subtracting the number of detractors from the number of promoters, a company arrives at its net promoter score.

Investing in people is the best investment an organization could do, as it is a long-run benefit for the organization. Quality experts recommend that businesses train workers at all levels to look for ways to improve quality and to ameliorate problems. Training takes on several dimensions, for example for starters, you should set up a new-employee initiation program that trains workers to focus on quality issues from their first day on the job. This is because it is easier to grow their determination to perform efficiently (in terms of quality) on the first day itself rather than on the later days when employees are used to their style of working - which is inefficiently. In addition, training workers to see the connection between their actions and, more broadly, their work ethic, and the company's overall performance can be done to increase their performance capability. Hence, by tying individual behavior to an overall system of work, and then showing where that system can, on occasion break down, you will be giving workers the information they need to be good stewards of your business.

Quality circles, by any other name, are teams of workers who are given the authority and responsibility for making a business better. By working in teams, teamwork can be develop, thus, there can be good influence with one another in a team. For example, if an employee $A$ in team $A$ is performing up to par, giving the best quality of service to the company's customers (retailers), employee A can indirectly influence other employees to follow his footsteps. As a result, the whole team A can achieve sustainability in their ability to provide the right service to the right customers at the right time and at the right place.

\section{CONCLUSION}

The obtained survey result shows that all 5 respondents are happy with their performance in terms of reliability. In terms of responsiveness, 2 out of 5 respondents dissatisfied because the time taken for their suppliers to solve an issue is too long. The respondents claim that after-sales service and reasonable price and good service are the important factor for the variable of assurance. Regarding the component of empathy, all 5 respondents are satisfied with their respective suppliers in understanding their in-store operations. Tangibility is supported by all the respondents because the trucks used are well-maintained and receipt of goods is provided once goods arrived at their doorstep. The consistency is poor, but most of the supplier resolves the issues immediately. Lastly, there are several ways that can be used to improve a particular service quality such as create a commitment, track mistakes, invest in training and development and organize quality circles.

\section{References}

1. Rajendran, S.D., and Wahab, S.N. (2017) Purchasing Intention towards Green Packaged Products: An Exploratory Study among Malaysian Consumers, 3rd International Conference on Advanced Research in Business and Social Sciences, 29-30 March, 347-355, Langkawi Malaysia.

2. Frohlich, M. T., \& Westbrook, R. (2001). Arcs of integration: an international study of supply chain strategies. Journal of operations management, 19(2), 185-200.

3. Selvachandran, G., Quek S.G., Smarandache, F. \& Broumi, S. (2018). An extended technique for order 
preference by similarity to an ideal solution (TOPSIS) with maximizing deviation method based on integrated weight measure for single-valued neutrosophic sets. Symmetry, Vol. 10, pp. 236-252. DOI: $10.3390 /$ sym10070236.

4. Selvachandran, G. \& Peng, X.D. (2018). A modified TOPSIS method based on vague parameterized vague soft sets and its application to supplier selection problems. Neural Computing and Applications, $\quad$ pp. 1-16. DOI: https://doi.org/10.1007/s00521-018-3409-1.

5. Agbor, J. M. "The Relationship between Customer Satisfaction and Service Quality: a study of three Service sectors in Umeå." (2011).

6. Andrew Sadauskas, 2011, What are the key qualities you look for in a supplier, beyond price? BUSINESS PLANNING, Available at https://www.smartcompany.com.au/startupsmart/ad vice/startupsmart-growth/make-suppliers-fight-foryour-business/

7. Knack, O. (2016).5 Qualities of a Good Supplier. Retrieved from https://www.intouchquality.com/blog/5-qualities-of-a-good-supplier

8. Rozhan Othman, Rohayu Abdul Ghani, 2008. Insight from industry: Supply chain management and suppliers'HRM practice, Supply Chain Management: An International Journal,13/4 (2008) 259-262 [DOI 10.1108/13598540810882143]

9. Apostolos Giovanis, George Pierrakos, Ioannis Rizomyliotis, Spyridon Binioris, (2018) "Assessing service quality and customer behavioral responses in hospital outpatient services: A formative measurement approach", International Journal of Quality and Service Sciences, Vol. 10 Issue: 2, pp.98-116, https://doi.org/10.1108/IJQSS-03-20170023
10. Creswell, J. W. (1998). Qualitative inquiry and research design: Choosing among five traditions. Thousand Oaks, CA: Sage Publications.

11. Tansey O. (2007). Process Tracing and Elite Interviewing: A Case for Non-probability Sampling. Retrieved from http://www.reading.ac.uk/web/files/spirs/tansey_ps_article_final.pdf

12. Wahab, S.N.. ., Bahar, N. \& Mat Radzi, N.A. (2019). An Inquiry on Knowledge Management in Thirdparty Logistics Companies. International Journal of Business Innovation and Research, DOI: 10.1504/IJBIR.2020.10024101.

13. Wong, C.H., Tan, G.W.H., Tan, B.I and Ooi, K.B. (2015). Mobile Advertising: The Changing Landscape of the Advertising Industry', Telematics and Informatics, Vol. 32 No.4, 720-734.

14. Teo, A.C., Tan, G.W.H., Ooi, K.B, Hew, T.S and Yew, K.T. (2015) 'The Effects of Convenience and Speed in M-Payment Usage', Industrial Management and Data Systems, Vol. 115 No. 2, 311-331

15. Sham, R., Wahab, S.N., \& Hussin, A.A.A. (2018). Smart Trolley Apps: A Solution to Reduce Picking Error. International Journal of Supply Chain Management, 7(5), pp. 294-302.

16. Wahab, S.N, Olugu, E.U., Lee, W.C., \& Tan, S.Y. (2018). Big data analytics adoption in Malaysia warehousing industry. The 32nd International Business Information Management Association Conference, IBIMA 2018, 2349-236515-16 November, Seville Spain.

17. Baker, T.L. (1994), Doing Social research (2ndEdn.), New York: McGraw-Hill Inc.

18. De Vaus, D.A. (1993), Surveys in SocialResearch (3rd edn.), London: UCL Press. 